\title{
Leprosy in the world today
}

\author{
H SANSARRICQ \\ Chief, Leprosy Unit, Division of Communicable Diseases, World Health \\ Organization, Geneva, Switzerland
}

In recent years the limited value of the existing strategy for leprosy control has become increasingly obvious, whereas it has been possible to propose new therapeutic regimens.

This has coincided with an increasing interest in leprosy on the part of governments of many endemic countries. One result of this interest has been the development of concerted efforts in leprosy research, particularly through the Scientific Working Groups on Immunology of Leprosy (IMMLEP) and Therapy of Leprosy (THELEP), aimed at the development of better tools to improve control. (The IMMLEP and THELEP Scientific Working Groups are part of the UNDP/ World Bank/WHO Special Programme for Research and Training in Tropical Diseases.)

A1so, many voluntary agencies have strengthened their collaboration with governments and WHO, and have substantially increased their financial contribution to leprosy activities. It is therefore most appropriate and timely to discuss the general situation of leprosy in the world today.

The magnitude of the leprosy problem

\section{IN GENERAL}

When expressed in terms of numbers of cases the leprosy problem does not, at first sight, seem very impressive as we shall discuss later. However, there are several factors which give the problem a far higher importance than that of mere statistics.

(a) Leprosy is generally a very chronic disease. The more severe forms tend to deteriorate with time and the most severe and contagious forms last for life. In addition, the life expectancy of patients is shortened by a few years and more so in the lepromatous forms. 
(b) In more than one-third of untreated or advanced cases leprosy results in disabilities which increase with time and are permanent. These disabilities affect mainly the $1 \mathrm{imb}$ extremities and the face including the eyes, resulting in serious impairment of working capacity and disruption of the social life of the patient.

(c) The disabilities and deformities of leprosy patients have in many cultural systems resulted in the belief, which may even be held by health workers, that the disease has necessarily incurable consequences. The degree of social ostracism resulting from this attitude makes the patients themselves convinced that their exclusion from the community is justified. A similar feeling of guilt may even be shared by the patients' families.

(d) As no preventive method is yet available, disease control is based only on appropriate treatment delivery. The epidemiological impact of treatment measures depends at first on a high proportion of cases being diagnosed at an early stage. The only diagnostic methods are clinical, and therefore require specialized knowledge and experience. Moreover, so far it is impossible to identify individuals at high risk of contracting the disease, and case detection has to be undertaken in large sections of the population. Then, treatment lasts for several years and even for 1 ife in lepromatous cases. In view of these difficulties, control programmes require the setting up of complex and expensive machinery creating many organizational and logistic problems.

(e) These problems are made more difficult because countries where leprosy is now a public health problem are tropical, developing countries which have inadequate manpower and financial resources to cope with leprosy and the many other and often greater public health problems with which they are faced.

Thus, the definition of the leprosy problem in global terms could best be summed up as the total human suffering and hardships due to the social and economic losses of the individual, the fainily and the community, caused by the disease in the present and in the future. However, there is no way of measuring human suffering and social losses; even economic losses are very difficult to assess. Therefore we have to use the only available indicators with their accepted limitations.

\section{STATISTICAL DATA}

(a) WHO surveys and others: Attempts have been made by WHO in 1966 (1), 1972 (2) and 1976 (3) respectively to gather global data on the leprosy situation by sending questionnaires to governments. In addition, use was made of information available in the Headquarters Leprosy Unit, from Regional offices, WHO consultants and scientific literature. A summary of the findings in the last WHO global survey which reported in general on the situation in 1975 is given in table 1 . 
Table 1. The situation of leprosy in the world in 1975

$\begin{array}{ccccc} & \text { No. of } & \text { Total no. of } & \text { Total no. of } & \text { Overall } \\ \text { Region } & \text { countries } & \text { estimated } & \text { registered } & \text { leprosy } \\ & & \text { leprosy cases } & \text { leprosy cases } & \text { prevalence }\end{array}$

\begin{tabular}{|c|c|c|c|c|c|}
\hline AFRO & 44 & $\begin{array}{c}1626466 \\
(12 \text { countíries })\end{array}$ & $\begin{array}{r}1 \\
(38\end{array}$ & $\begin{array}{l}398220 \\
\text { countries) }\end{array}$ & $\begin{array}{l}4.6^{\circ} / 00 \\
(38 \text { countries })\end{array}$ \\
\hline AMRO & $\begin{array}{l}44 \\
\text { (countries }+ \\
\text { territories) }\end{array}$ & 400000 & (a11 & $\begin{array}{l}241248 \\
\text { countries) }\end{array}$ & $0.44^{\circ} / 00$ \\
\hline EMRO & 23 & $\begin{array}{c}81435 \\
(5 \text { countries })\end{array}$ & $(22$ & $\begin{array}{l}63236 \\
\text { countries) }\end{array}$ & $\begin{array}{l}0.27^{\circ} / \text { oo } \\
\text { (by reg. cases } \\
\text { in } 22 \text { count- } \\
\text { ries) }\end{array}$ \\
\hline EURO & 20 & - & $(20$ & $\begin{array}{l}20452 \\
\text { countries) }\end{array}$ & $\begin{array}{l}0.05^{\circ} / 00 \\
(20 \text { countries })\end{array}$ \\
\hline SEARO & 11 & $\begin{array}{c}4510328 \\
(9 \text { countries })\end{array}$ & $\begin{array}{r}1 \\
(8\end{array}$ & $\begin{array}{l}748468 \\
\text { countries) }\end{array}$ & $\begin{array}{l}5.0^{\circ} / 00 \\
\text { (estimate } \\
\text { based on } 9 \\
\text { countries) }\end{array}$ \\
\hline WPRO & 29 & $\begin{array}{l}\quad 2000000 \\
\text { (no data availab } \\
\text { for China, } \\
\text { Kampuchea, Laos, } \\
\text { Hong Kong, Papua } \\
\text { New Guinea) }\end{array}$ & le $(22$ & $\begin{array}{l}128325 \\
\text { countries) }\end{array}$ & $\begin{array}{l}1.82^{\circ} / \text { oo } \\
\text { (for total } \\
\text { area) }\end{array}$ \\
\hline
\end{tabular}


Since the last WHO global survey new efforts to update figures on the leprosy situation have been made at national and WHO regional levels, as part of the recently established system of Country and Programme Profiles. In addition, the International Federation of Anti-Leprosy Associations (ILEP) has been collecting information from various sources which is compiled in a loose-leaf atlas, allowing continuous updating of the figures and maps (4). The main points which emerge from these efforts are the following.

(i) Overall estimate of leprosy cases: In the 1976 WHO global survey, two Regions, the South-East Asia Region and the Region of the Americas, provided estimates from virtually all their countries. In other Regions some extrapolations had to be applied. The final estimates by Region and overall were as shown in table 2, with a total number of estimated leprosy cases in the world of 10595000 .

Table 2. Estimated leprosy cases by WHO Regions (1975)

\begin{tabular}{lr} 
WHO Regions & Number of cases \\
\hline Africa & 3500000 \\
Americas & 400000 \\
South-East Asia & 4510000 \\
Europe & 25000 \\
Eastern Mediterranean & 160000 \\
Western Pacific & 2000000 \\
\hline Total & 10595000 \\
\hline
\end{tabular}

The overall estimates made in previous surveys had been 10876000 and 10407200 in 1966 and 1972 respectively. (ii) Registered cases: In the last WHO global survey information was provided by 142 countries with a total population of 2699251 000, in which the total number of reported cases was 3610 132. In 110 countries it was possible to compare the number of patients known in 1966 and 1975. In this group of countries ther $\epsilon$ were in 1966, 2788298 cases of leprosy registered. In 1975, nine years later, there were 3247 868, representing an increase of 459570 cases, i.e. 17\% more than in 1966.

When the figures of the 1976 wHO global survey are compared with those of the later country and programme profiles, no striking difference appears in the various regional totals with one important exception, South East Asia. In this region, one country, India, has 
reported a dramatic increase in its number of registered patients which was 1320000 in 1974 (1976 WHO survey) and 2600000 in the 1980 country and programme profile.

The most recent figures for registered cases by continent collected by ILEP show that 4334602 cases were known in 1980 . Altogether it could be assumed that at least 5000000 leprosy patients are registered in the world today, this representing an increase of roughly $75 \%$ over the last 15 years. But about one-half of the presently known leprosy patients are in India.

The rate of known cases in proportion to the populations of these countries was calculated. If countries are grouped according to the different levels of these rates, from 0.5 per 1000 to 20 per 1000 and over, figures of total population corresponding to these different levels can be arrived at, as shown in table 3 .

Table 3. Populations corresponding to various levels of known leprosy prevalence

\begin{tabular}{lc}
\hline Rates of known prevalence & Population \\
\hline $0.5-0.9$ per 1000 & 402806000 \\
$1.0-4.9$ per 1000 & 877635000 \\
$5.0-9.9$ per 1000 & 79812000 \\
$10.0-19.9$ per 1000 & 22414000 \\
$20+\quad$ & 535000 \\
\hline
\end{tabular}

Various studies have demonstrated regional variations in the different clinical or epidemiological parameters of leprosy, and the WHO surveys have confirmed this pattern. These variations may have their origin in genetic, nutritional, socioeconomic factors, ets., which remain to be elucidated.

(iii) Treated cases: The figures reported in the 1976 WHO global survey showed for four WHO Regions average proportions of treated cases varying from $71 \%$ to $86 \%$, and average proportions of regularly treated patients in three Regions from $42 \%$ to $53 \%$.

( $1 v)$ Disabilities: One-third of the countries questioned in 1976 provided information on this subject, but it was only indicated clearly in a few cases that the figures related to all classes of disability, including anaesthesia, or referred only to the two most serious degrees of disability. 
There were wide variations in the reported figures. Of 28 countries, 18 reported disability rates above $20 \%$, 4 countries rates between 10 and $20 \%$ and 6 countries below $10 \%$.

\section{(b) Discussion}

(i) Incompleteness and inaccuracy of information: It is evident from the many incomplete questionnaires received in the WHO surveys, and also from data collected from other sources, that the existing recording and reporting systems used in many countries are defective and valuable data are not being recorded or are incomplete. The frequent failure to make estimates of the overall prevalence in countries is particularly to be regretted since planning for the future depends on such estimates. (ii) Value of the overall estimate: The estimated total of 10 to 11 million leprosy cases has often been considered to be "rather conservative". However, it is doubtful whether a higher estimate would better reflect the true situation in view of the following factors:

(a) The estimates of existing cases at country level have been based in general on rather empirical assumptions. (b) Over a period of 15 to 20 years there has been little variation in the overall estimates, despite the demographic explosion in highly endemic countries. (c) During the last 15 to 20 years there has been a wide gap between the estimated number of leprosy cases and cases reported as registered. The recent decrease in this gap is mainly due to increased case detection activities in one country. (iii) Overall efficiency of case-finding activities: If one takes into account the fact that several hundred thousand patients have been released from control or have died during the period 1971-1975, the increase by $17 \%$ of the registered cases indicates that casefinding activities have been appreciable, though not striking, during this period. In addition, the two-fold increase in registration of cases in India from 1974 to 1980 is to be appreciated. However, the still large gap between the number of known and estimated cases clearly shows that a considerable effort is needed to strengthen the network of health services involved in leprosy control, and to increase their activity.

\section{THE RELATIVE IMPORTANCE OF LEPROSY}

Leprosy is in general only one of the many public health problems which affect tropical developing countries. In this connexion we have recently (5) made a comparison of leprosy with the most prevalent parasitic diseases which are the most common communicable diseases in these areas. We have also included in this comparison 
the other major mycobacterial disease, tuberculosis, which although universally widespread, is more prevalent in tropical countries.

This comparison, which refers only to some of the communicable diseases prevalent in tropical endemic countries, clearly demonstrates the magnitude of the many challenges facing their governments. Of course not all countries are subjected to all these threats simultaneously, but it is not uncommon to find one country faced with several of them. It is therefore essential when assessing the importance of leprosy in one given country to put it into the general perspective of all major health problems.

When the comparison is made at global level it appears that: (a) the global morbidity of leprosy is low as compared with most of the other diseases; (b) the mortality of leprosy is quite low as compared with, for instance, tuberculosis or African trypanosomiasis; (c) a large majority of leprosy patients are not bedridden, as is the case in some other tropical diseases.

However, leprosy appears to be a very serious problem if one considers the following factors: (a) the populations exposed to the risk of contracting leprosy are very large: the countries with a known prevalence above one per thousand had in the last WHO survey a total population of about one billion. Only tuberculosis and malaria show populations at a risk of contracting the disease higher than for leprosy. (b) A significant proportion of leprosy patients face the threat of permanent and progressive physical and social disability.

Present achievements of leprosy control

CLASSICAL STRATEGY FOR LEPROSY CONTROL

In the 1950s it was believed that dapsone monotherapy of all infectious cases would result in the control of leprosy. Subsequently, with the descriptions of the mouse foot pad technique for the culture of M. leprae by Shepard $(6,7)$, and of the measurement of the morphologic changes of $M$. during effective chemotherapy (8), it was possible to assess directly the antimicrobial activity of drugs against M. leprae. It was then possible to demonstrate that at least $99 \%$ of the viable M. initially present in a lepromatous lesion are killed during the first three months' administration of dapsone in a daily dosage of 50 to $100 \mathrm{mg}$. This information suggested that truly effective chemotherapeutic tools were indeed available, both for the treatment of individual patients and for the control of leprosy.

On this basis was established the classical strategy for leprosy control which was recommended by WHO. This strategy was aimed at interrupting the transmission of the disease by reducing the 
reservoir of infection, in other words, it was a secondary prevention approach.

Leprosy control programmes have been based on early casefinding, follow-up of contacts, and prolonged chemotherapy of patients by dapsone, both to limit transmission of the infection in the community and to prevent the disabilities that characteristically occur in various types of leprosy. Dapsone has been used for the past 30 years. Patients with paucibacillary leprosy are generally treated for at least 3 to 5 years; patients with lepromatous leprosy must be treated for life. Although therapy with dapsone is safe, and supplies of the drug are cheap, few developing countries can sustain the burden imposed by the need to treat patients for many years, or even for their lifetime. Moreover, patient compliance with self-administered treatment is known to be poor, and few leprosy control programmes are able to provide adequate supervision of the patients' drug-taking. Thus, in most areas of the world in which leprosy is endemic, many known patients are not treated at all, many who are treated take their treatment with insufficient regularity, and there are not enough resources for the case-finding activities needed to bring into the control programme those patients who are not registered.

In view of these difficulties, attempts were made to add to the existing strategy a primary prevention component, i.e. protection of the exposed individuals by a vaccine.

In the absence of an M. leprae-derived vaccine, BCG has been tested for its preventive effect against leprosy in long-term vaccine trials, notably in Uganda (9), Papua New Guinea (10) and Upper Burma (11). The results of these trials showed large variations. Reported overall protection ranges from $80 \%$ for Uganda to $20 \%$ for the WHO trial in Burma. In the latter, in which observations have been carried out for 12 years, a steadily growing number of multibacillary forms of leprosy are being diagnosed, indicating that BCG has either no, or a very limited, protective effect against these forms of leprosy (12).

The XIth International Leprosy Congress (Workshop on Epidemiology and Control, including Field Therapy, XI International Leprosy Congress, Mexico City, November 1978) concluded that BCG has a limited prophylactic value and stressed the need to develop a more effective vaccine against leprosy (13).

Regarding other means of primary prevention, with present methods the application of chemoprophylaxis on a mass scale will not be practicable, although studies on chemoprophylaxis have established their moderate protective value. 


\section{ACH IEVEMENTS}

In principle, overall figures, because of the wide gap between the number of known patients who could receive treatment and the number of estimated cases, cannot give any information on the possible impact of the classical strategy for leprosy control. This is simply because, to be effective, a strategy based on secondary prevention is likely to require that a high proportion of the reservoir cases be subjected to appropriate treatment. So it is not surprising to see that over the last decades no substantial change has been observed in the overall leprosy situation, as we have discussed earlier.

It is, however, interesting to see if, when it has been possible to apply the above-described classical strategy, any impact has been made on the epidemiological situation. In a few countries or areas this sort of comparison has been possible, and we shall now discuss the results observed.

(a) Thailand: In the Khon Kaen Province (14) control operations started in 1956. In 1962, a WHO Leprosy Assessment Team (LAT) carried out a random sample survey in this province and estimated the prevalence as 12.37 per thousand ( 8900 cases) in a population of 720000 .

In 1972 another sample survey was carried out and showed that the estimated prevalence was 3.75 per thousand (3290 cases), a decrease of $71.7 \%$.

(b) Burma: The LAT carried out a random sample survey in the districts of Shwebo and Myingyan in 1963. The prevalence rate was estimated at 32.16 per thousand for Shwebo (18 800 cases) and $44: 34$ per thousand for Myingyan (28 500 cases). Control operations had started in both areas in 1957. The population at the time of the LAT survey was 584608 in Shwebo and 643940 in Myingyan.

A random sample survey was carried out in 1973 in areas in Central Burma (15) near the two districts surveyed in 1963. The survey report gives an estimated prevalence of 13.5 per thousand for the combined areas (16 050 cases). The report assumes that the situation in the areas in 1963 was not greatly dissimilar from Shwebo and Myingyan, and thus there may well have been a reduction in the total number of cases by $50 \%$ in that area. (c) Upper Volta: In this country case detection mass surveys were carried out annually from 1955 with total coverage of the population. In 1966, in a population of 4016 960, 140662 leprosy cases were registered and in subsequent years, with the same efficient case detection system operating, the total number of cases, the corresponding prevalence and the annual number of new cases detected decreased progressively. 
A random sample survey was conducted with WHO assistance in 1976 (16) from which it was concluded that in the period 1966-1976 the prevalence of leprosy had been reduced from 35.01 per thousand to 5.26 per thousand; a decrease of $85 \%$.

(d) India: An assessment of the national leprosy control programme at Tirukoilur, Tamil Nadu, South India, gave the following conclusions. A prevalence of 63 per thousand in 1955-57 decreased to 45 per thousand in 1961-63. It then stabilized showing 47 per thousand in 1964-66 and 43 per thousand in 1967-73.

From these evaluations it can be concluded that substantial reductions in prevalence of up to $80 \%$ or more have been possible in well organized and well conducted control programmes based on dapsone monotherapy. However, in the same programmes it has not been possible to demonstrate a parallel decline in incidence, although in Burma, Thailand and Upper Volta a steady decline in case-detection rates has been observed when case detection effectiveness has remained in a stable state over the periods of observation.

In any case it is important to note that in such programmes the leprosy cases which remain on the registers are, in a high proportion lepromatous cases, those who are the core of the reservoir of infection. Moreover, these lepromatous cases are those whose treatment has given rise to new problems in recent years.

Problems recently arisen

In fact, recent studies have demonstrated that dapsone therapy falls short of the ideal for two important reasons. First, M. 1eprae, like M. tuberculosis, throws off drug-resistant mutants with a. frequency that probably approaches $1: 10^{6}$ (one per million). The evidence that this is the case has come from studies in Malaysia (17), Costa Rica (18), Ethiopia (19), Israel (20), India (21), the Philippines (22) and Upper Volta (23). Further resistance surveys are currently being carried out in particular as part of the THELEP activities. The list of countries where resistance has been found must by now exceed 25. The risk of relapse associated with the emergence of dapsone-resistant $M$. ranges from about $2 \%$ in Malaysia and Israel to as great as $3 \%$ per annum in Ethiopia. The greater risk appears to be related to the practice in some areas of initiating dapsone therapy with a low dosage, or with a derivative or analogue that provides only a low dosage of dapsone. Another important factor could be irregular drug intake. Although dapsone and other sulfones have been used in the chemotherapy of leprosy for as long as 30 years, relapse of leprosy associated with dapsone-resistant $M$. has been recognized for only about 15 years. The recent studies have shown that the time from 
start of treatment to relapse with drug-resistant organisms, which may be shorter than one year in tuberculosis, is at least five years and as long as 20 years in leprosy.

It was to be anticipated that when contacts are infected with dapsone resistant mutants, clinical leprosy evolving in some of these individuals would be with M. leprae having primary resistance to dapsone. Such cases of leprosy with primary resistance to dapsone have been demonstrated in Ethiopia (24), India (25), Malaysia (26), Philippines, the USA (27) and Mali.

Dapsone therapy of leprosy falls short of the ideal in a second important respect. It has been recognized for some time that cessation of treatment of lepromatous leprosy patients with dapsone carried a great risk of relapse even when this treatment had been followed with reasonable regularity for more than ten years. The demonstration of surviving dapsone-susceptible M. 1eprae in several tissues of seven of 12 patients who had been treated for at least ten years with supervised dapsone therapy in full dosage suggests that microbial persistence, a feature of tuberculosis and other infectious diseases of man, is also a feature of lepromatous leprosy (28).

In order to prevent the emergence of secondary dapsone resistance, it is agreed that multiple- drug regimens should be used for the treatment of lepromatous (LL) and borderline (BL, BB) cases. The WHO Expert Committee at its fifth meeting in 1976 (29) tentatively recommended for the treatment of newly diagnosed lepromatous and borderline cases that combinations of dapsone be given daily indefinitely, plus either rifampicin given daily for a few weeks, or clofazimine given daily or three times a week for a few months. For the treatment of dapsone resistant cases, the Committee recommended a combination of clofazimine to be given daily indefinitely, plus rifampicin given daily for a few months.

It is to be noted here that rifampicin has an extraordinarily rapid killing action on M. leprae. For instance, a single dose of $1200 \mathrm{mg}$ of rifampicin accomplishes as much bacterial killing in a few days as dapsone monotherapy in a few months (30). However, persisting M. leprae have been demonstrated following both monotherapy with rifampicin and even combined therapy with rifampicin and dapsone, each drug being administered daily at full dosage during periods from six months to several years (30).

Needs and prospects

NEED FOR IMPROVED TECHNOLOGIES

(a) Improvement of äiagnostic tools: While there is no method for 
primary prevention, our strategy will have to continue to be based only on secondary prevention, which implies the detection of a high proportion of cases, priority being given to the detection of infectious forms. Personnel appropriately trained in the diagnosis of leprosy based on clinical findings are required. In addition, active methods for case detection have to be used as many patients are afraid to seek treatment because of the prejudice against leprosy. Hence the requirements in personnel both in number and level of training are high, in countries which have limited resources and many other health problems.

Even if more effective drug regimens were put into use, it is to be feared that their epidemiological impact would not be as high as desired. In those programmes based on dapsone monotherapy and conducted under the best possible conditions, there was a substantial reduction in prevalence but little decrease in incidence, suggesting that before infectious cases receive treatment they have already spread leprosy infection among a large proportion of their contacts. It seems likely that the use of more potent antileprosy drugs, even if it reduces the infectious period of lepromatous cases by a few months as compared to dapsone monotherapy, would not greatly affect the spread of $M$. leprae in the community. However, such a hypothesis remains to be investigated.

Therefore, there is a strong need for a test for early diagnosis of the lepromatous form of leprosy. Some of the tests currently being developed by the IMMLEP SWG may meet this need. Such individuals could then be put under close surveillance or even given prophylactic treatment.

(b) Improvement of treatment methods: Although it is now four years since the WHO Expert Committee on Leprosy recommended the use of combined drug therapy for lepromatous leprosy in its report published in 1977, so far, in fact, very few countries have established a method of combined drug treatment which is both systematic and applicable on a national scale. We think there are two reasons for this: (1) the financial aspect: there are, however, a number of organizations which are prepared to assist financially the introduction of combined drug treatment; (2) the operational aspect: the most effective recommended treatment regimens prescribe rifampicin to be given daily for a minimum of two weeks, or for 2-3 months, in both cases under supervision. It seems that this requirement of daily supervised therapy for a few weeks or months has met in general with insuperable difficulties.

However, it might be possible to solve the operational problem. Recently evidence has been provided that rifampicin (31) and clofazimine (32) are effective even when administered in intermittent doses, that is, monthly. This could be done in countries 
where contact with patients is monthly - as is the general rule. When designing new regimens for control purposes, one has also to take into account the fact that the incidence of secondary resistance to dapsone is bound to increase among multibacillary cases, and that primary resistance will also be increasing in all forms of leprosy. Therefore, triple drug regimens are to be logically put into practice. Dapsone should remain part of these regimens for those patients with dapsone-sensitive bacilli. But since it will not be possible to identify resistant cases under field conditions, two bactericidal non-dapsone drugs are required for lepromatous patients with dapsone-resistant M. leprae, both to be effective on the dapsone-resistant bacilli and to prevent the emergence of resistance to each other.

Another problem is the long duration of treatment. In this respect a regimen including daily unsupervised dapsone combined with supervised monthly rifampicin and clofazimine will soon be put into experiment by THELEP. This regimen includes an important feature. It is intended to stop treatment after a period of two years and then assess the rate of relapses. If this relapse rate would be less than $1 \%$ per annum, it could be concluded that such a regimen could allow finite duration of treatment in inactive lepromatous cases.

With respect to non-lepromatous cases, it would be also beneficial for economic reasons and, in addition, would ensure a higher patient compliance with regimens of a shorter duration than at present. THELEP has decided to prepare a protocol for drug trials in non-lepromatous leprosy which would answer the question.

(c) Need for immunoprophylactic methods: Present and future treatment methods may be able to solve the problems of resistance to dapsone and other antileprosy drugs, and the problem of persisters, but the need for arduous case-finding and case-holding activities would remain, even if an objective diagnostic test for lepromatous leprosy could be developed. Adequately trained personnel, sufficient financial resources and good logistics would still have to be provided. Therefore, the development of a tool for primary prevention, i.e. a vaccine of good protective value, would be an invaluable asset. This is the main objective of the IMMLEP programme, and work on such a vaccine is progressing very satisfactorily. We believe that it may be possible to launch field trials for the IMMLEP leprosy vaccine in two or three years from now, and have results after some ten more years.

\section{NEED FOR IMPROVED PROGRAMME MANAGEMENT}

The progress in many national leprosy control programmes so far has been disappointing, mainly because of failure to define the true 
magnitude of the problem, or to provide a true estimate of the level of human and financial resources required, and the length of time needed to attain the programme objectives.

Therefore, governments should first decide on the prinrity to be assigned to leprosy within their other public health commitments, before embarking on renewed leprosy control activities. A realistic appreciation of the magnitude of the leprosy problem, as well as of the resources required, is therefore necessary. To this end, it would be advisable in many endemic countries to undertake random sample surveys for evaluation of both epidemiological and operational aspects. Such surveys are expensive and time-consuming, but it is becoming increasingly evident that their usefulness outweighs the costs and efforts they require.

For the same reasons, planning and programming of leprosy control measures are essential. Here again, since leprosy endemic countries have many other serious public health problems, it is very important that leprosy activities are combined as much as possible with other health activities in order to improve the cost/ effectiveness ratio of the leprosy programme. This process should take into account the stigma attached to leprosy, which was why specialized programmes were established in many countries to deal more effectively with the problem. The only rational general approach to deal with this aspect of the leprosy problem is to aim at maximum community participation. An opportunity for this could well be presented by the primary health care (PHC) approach, which has recently been accepted by all wHO Member States. In addition, the chronicity and diffuse distribution of leprosy render it a disease best dealt with by widely distributed health units, since coverage of the whole country must be a general objective.

A consequence of the PHC approach is that the care of leprosy patients can no longer be regarded as the task of a specialized part of the health services and of voluntary bodies, and it is generally recognized that leprosy control cannot be achieved without the full resources of the health care system and of the community. In endemic countries, therefore, the basic training of all professional and auxiliary staff should include an understanding of the disease. Consequently, due consideration must be given to the training requirements at all stages of the planning and programming process. Those responsible for such a programme should be trained in planning and programming techniques.

\section{NEED FOR IMPROVED COOPERATION}

The promotion of self-reliance is essential in any strategy aimed at solving any problem in developing countries. The importance of this principle cannot be overemphasized and it is now central to all WHO 
efforts. This principle is also applicable in leprosy, but certain special considerations are involved in this particular field. At present in most endemic countries leprosy activities are actively supported by voluntary organizations from developed countries. This support which has made possible many achievements is most appreciated. However, every endeavour should be made to increase the involvement of nationals particularly at high responsibility levels. This will require the concerted efforts of all concerned, and particularly from governments, which should, for instance, provide career opportunities for their personnel. It also requires a change in attitude on the part of voluntary organizations, which is already taking place, so that they accept to provide financial support and leave the responsibility for technical policy, organizational problems, etc., entirely to national authorities at all levels.

\section{Conclusions}

In summary, the constraints for leprosy control result mainly at present from inadequate infrastructure, from inadequate methodologies for case detection, and the severe shortcomirgs of dapsone monotherapy.

Possibilities for improving treatment methods already exist by means of combined chemotherapy, but there has been difficulty in putting them into practice. It might be possible, however, to solve these difficulties by intermittent administration of drugs. At the same time, by increasing the number of drugs in the regimens, their efficacy could be increased.

On the whole, based on presently available concepts, the development of an effective antileprosy vaccine remains an essential requirement for an effective strategy for leprosy control.

As for what WHO intends to do, in close collaboration with its Member States during the next decade, this can be summarized as follows.

Improved technologies for case detection, especially early detection, treatment with chemotherapy, case holding and contact follow-up will be promoted through the development of more effective control planning, programme management and training. Field application will be encouraged of significantly more effective control methods expected from the increased efforts in leprosy research. Curricula incorporating proven approaches will be constructed for the training of all levels of health workers - from the medical undergraduates to the primary health care personnel. The participation of national experts will be promoted in management and evaluation. Collaboration with international, bilateral and voluntary agencies will be encouraged. According to the progress made, operational studies on vaccination will be initiated. 


\section{References}

1 Bechelli LM, Martinez Dominguez V. The leprosy problem in the world. Bull WHO, 1966, 34, 811-826.

2 Bechelli LM, Martinez Dominguez $V$. Further information on the leprosy problem in the world. Bull. WHO, 1972, 46, 523-536.

3 World Health Organization. Leprosy. Wkly Epidem Rec, 1979, 54, 17-23.

4 International Federation of Anti-Leprosy Associations (ILEP). Leprosy Atlas. London, England, June 1981. (Loose-leaf folder).

5 Sansarricq H. The Kellersberger Memorial Lecture: General situation of leprosy in the world. Ethiop Med J, accepted for publication 1981 .

6 Shepard CC. The experimental disease that follows the injection of human leprosy bacilli into footpads of mice. J Exp Med, $1960 \mathrm{a}, 112,445-454$.

7 Shepard CC. Acid-fast bacilli in nasal excretions in leprosy and results of inoculation of mice. Am J Hyg, 1960 b, 71, 147-157.

8 Waters MFR, Rees RJW. Changes in the morphology of Mycobacterium leprae in patients under treatment. Int J Lepr, 1962, 30, 266-277.

9 Stone MM, Brown JA Kinnear, Sutherland I. The trial of BCG vaccination against leprosy in Uganda. East Afr Bull, 1973, 2 , 15-24.

10 Russell DA. BCG vaccination in the prophylaxis of leprosy. The Karimui Research Group. Paper presented at the Tenth International Leprosy Congress, Bergen, 13-18 August 1973.

11 Bechelli LM, Kyaw Lwin, Gallego Garbajosa P. et al. BCG vaccination of children against leprosy: nine-year findings of the controlled WHO trial in Burma. Bull WHO, 1974, 51, 93-99.

12 Martinez Dominguez V, Gallego Garbajosa P, Mg Mg Gyi et al. Epidemiological information on leprosy in the Singu area of Upper Burma. Bull WHO, 1980, 58, 81-89.

13 Committee 5 (1979) Workshop in epidemiology and control including field therapy. Report. Int J Lepr, 1979, 47, 304-306. (Transactions of the Eleventh International Leprosy Congress, Mexico, 13-18 November 1978).

14 Pakda Anan C, Sanaya Korn, Chaiyan K, Seal KS. Some results from sixteen years of leprosy control in the Khon Kaen province of N.E. Thailand. Lepr Rev, 1974, 45, 205-210.

15 Kyaw Lwin, Zuiderhoek B. Case detection rates for Central Burma (1962-1972). Int J Lepr, 1975, 43, 125-128.

$16 \mathrm{Blanc}$ M. Evaluation de la campagne de masse contre la lèpre en Haute Volta après đix ans d'activité (1966-1976). Acta Leprol (Geneva), 1978, No 73, 39-58.

17 Waters MFR. The diagnosis and management of dapsone-resistant leprosy. Lepr Rev, 1977, 48, 95-105. 
18 Peters JH, Shepard CC, Gordon GR et al. The incidence of DDS resistance in lepromatous patients in Costa Rica: their metabolic disposition of DDS. Int J Lepr, 1976, 44, 143-151.

19 Pearson JMH, Haile GS, Barnetson R STC et al. Dapsone-resistant leprosy in Ethiopia. Lepr Rev, 1979, 50, 183-199.

20 Levy L, Rubin GS, Sheskin J. The prevalence of dapsone-resistant leprosy in Israel. Lepr Rev, 1977, 48, 107-112.

21 Taylor PM, Chacko CJG, Job CK. Study of sulphone resistance in leprosy patients in India. Lepr Rev, 1976, 47, 5-11.

22 Fajardo TT, Abalos RM. A study of proven dapsone-resistant leprosy in Cebu, Philippines. Int J Lepr, 1979, 47, 415. (Transactions of the Eleventh International Leprosy Congress, Mexico, 13-18 November 1978).

23 Pattyn SR, van Loo G, Sansarricq H. Quatre cas de lèpré dapsone résistants en Haute-Volta. Méd Afr Noire, 1981, 28, 147-148.

24 Pearson JMH, Haile GS, Rees RJW. Primary dapsone-resistant leprosy. Lepr Rev, 1977, 48, 129-132.

25 Girdhar BK, Sreevatsa S, Desikan KV. Primary sulphone resistance. A preliminary report. Lepr in India, 1978, 50, 352355.

26 Waters MFR, Laing AB, Rees RJW. Proven primary dapsone resistance in leprosy - a case report. Lepr Rev, 1978, 49, 127-130.

27 Jacobson RR, Hastings R. Primary sulfone resistant leprosy. Int J Lepr, 1978, 46, 116. (Twelfth Joint Leprosy Research Conference, U.S.-Japan Cooperative Medical Science Program, Boston, Massachusetts, USA, 27-29 September 1977).

28 Waters MFR, Rees, RJW, MCDougall AC et al. Ten years of dapsone in lepromatous leprosy: clinical, bacteriological and histological assessment and the finding of viable leprosy bacilli. Lepr Rev, 1974, 45, 288-298.

29 wHO Technical Report Series, 1977, No 607 (Fifth report of the WHO Expert Committee on Leprosy).

30 Committee 4. Workshop on experimental chemotherapy. Report. Int J Lepr, 1979, 47, 297-303. (Transactions of the Eleventh International Leprosy Congress, Mexico, 13-18 November 1978).

31 Laing ABG, Waters MFR, Rees RJW. Four-weekly "pulse" therapy with rifampicin in sulphone-resistant lepromatous leprosy interim report. Int J Lepr, 1979, 47, 437. (Transactions of the Eleventh International Leprosy Congress, Mexico, 13-18 November 1978).

32 Collaborative effort of the U.S. Leprosy Panel (U.S.-Japan Cooperative Medical Science Program) and the Leonard Wood Memorial. Spaced clofazimine therapy of lepromatous leprosy. Amer J Trop Med Hyg, 1976, 25, 437-444. 